\title{
Research into Linyi's rural precision poverty relief model driven by the government, market, and society
}

\author{
Yu Zhang \\ Feixian Brach,Linyi University, Feixian,Linyi,Shandong,China \\ 18265187698@163.com
}

Keywords: Government; Society; Linyi's rural area; Precision poverty relief

\begin{abstract}
Precision poverty relief requires participation of not only the government, but also the society, market and public. This is the idea of diverse coordinated precision poverty relief. Currently, Linyi's rural precision poverty relief has the following problems: weak basic conditions and inadequate industrial support; outflow of rural workforce, resulting in the serious phenomenon of "empty village"; lack of villagers' awareness and motivation of self-development, and serious reliance; contradiction caused by diverse participation and mutual coordination of poverty relief subjects; contradiction between diversification of poverty relief fund items and launch system integration; unsmooth open poverty relief mechanism. Currently, it is necessary to establish the concept of "proceeding from needs of impoverished households" in Linyi's current rural precision poverty relief, set up a communication platform, coordinate participation of multiple poverty relief subjects, give full play to the main role of farmers, government, enterprises and schools, integrate multiparty resources, and promote the open-ended poverty relief to form economies of scale.
\end{abstract}

\section{政府、市场、社会三元驱动的临沂农村精准脱贫模式研究}

\author{
张玉 \\ 临沂大学费县校区, 费县, 临沂, 山东, 中国 \\ 18265187698@163.com
}

关键词：政府; 市场; 社会; 临沂农村; 精准脱贫

中文摘要：精准脱贫不仅需要政府参与, 还需要社会、市场和公众协同参与, 需要树立多元 协同精准脱贫的思想。目前临沂农村精准脱贫存在如下问题: 基础条件相对薄弱, 产业支撑 略嫌不足; 农村青壮年外出务工, 致使空壳村严重; 农民自身发展意识与动力薄弱, 依赖思 想严重; 多主体参与和相互协调间的矛盾; 资金来源多样与投放系统性的矛盾; 精准脱贫体 制机制不顺畅等问题。在当前临沂农村精准脱贫工作中, 要确立 “一切从贫困户需求出发” 的理念, 搭建沟通平台, 协调各主体参与, 充分发挥农民主体、政府主导、企业主力、学校 主培的作用，整合多方资源，推动精准脱贫。

1. 引言

精准脱贫既是政府的责任，又是社会共同体和个人应负的责任。目前我们所实施的精准 扶贫是直接面对困难户的扶贫, 需要大量资源, 仅靠中央政府远远不能解决, 需要吸纳社会 力量广泛参与, 实现多元主体共同合作扶贫。强调的是, 精准扶贫不但需要政府参与, 也需 要社会、市场和公众共同参与, 这是多元治理精准脱贫的思想, 是治理贫困的一种理想模式。 


\section{2. 多元共治精准脱贫的理论基础一一协同理论}

任何一个管理系统中，各元素间的合作、协调如可合成推动效力，拉动事物共同发展， 导致事物间属性相互加强, 沿着积极的道路前进, 那么就会产生 “ $1+1+1>3$ ” 的协同效应。反 之，整个系统会陷于一种失控失序的状态，结果只能是 “ $1+1+1<1$ ” 甚至 “ $1+1+1<0$ ”。精准扶 贫战略背景下，多元化是临沂农村地区精准脱贫的必然趋势，这决定了治理贫困必须将协同 理论引入扶贫实践中，使政府、市场及社会各主体间保持协同互动，以持续提升扶贫的精准 性, 实现扶贫绩效最大化。精准脱贫工作是一个庞杂的系统工程, 从参与的主体上来讲, 多 元协同扶贫不但需要地方政府及其部门的协调, 还需要政府与市场、社会的协同, 需要全面 发动群众、企业和社会组织等各方力量协同合作，体现精准扶贫实践创新的要义。

\section{3. 临沂农村精准脱贫工作的现状及问题}

\section{1 基础条件薄弱, 产业支撑不足}

调查中发现, 整体比较富裕的村, 或者大部分劳动力外出务工, 或者实现了农业产业化。 外出务工可以致富, 不过致富层次不齐; 实现农业产业化的村致富层次比较整齐。贫困地区 之所以贫困, 主要因为当地农民缺乏致富的技术, 没走上农业产业化道路。有的农民们发现 了可开发的项目或需要引进新品种、新技术, 但苦于基础条件薄弱, 且没有足够的资金支持 而难于实现。

\section{2 青壮年外出务工, 空壳村现象严重}

近年来，农村外出打务工的青壮年越来越多。一是因为村庄的地理位置偏僻. 土地资源禀 赋不足, 以致农业发展受限; 二是村庄普遍存在吃水用电比较困难、交通不便、通信不畅及 教育医疗卫生各方面条件较差。加上目前外出务工和离乡创业的现象较普遍, 致使农村青壮 年劳动力流失, 许多村只留下无法离开的老弱病残独自过活, 大量的土地抛荒, 房屋空置, 村庄显得极为颓败，人口“空心”诱发了经济 “空壳”。

\section{3 农民自身发展动力、意识薄弱}

通过与部分扶贫干部以及农民沟通，发现很多农民已经习惯了懒惰和闲散，不愿勤劳致 富。他们不知道需要学什么技术, 或者能学会哪些技术。即便年轻一代的农民, 尽管受过义 务教育, 但是对当代社会需要的信息、技术也一无所知, 不敢接受培训。

\section{4 扶贫资金来源多样化与投放使用的整合性之间的问题}

精准扶贫的主体多元化, 导致扶贫所需资源在渠道和形式上多样化, 这些各种形式的扶 贫资源存在优化整合、开放共享的需求。

\section{5 精准扶贫体制、机制不顺畅的问题}

建立在扶贫主体多元化和扶贫资源多样化基础上的精准扶贫, 需要更系统、更协调的体 制机制为保障, 以便形成合力, 精准有效。部分贫困人员急需的项目缺乏资金, 不必要的项 目却有配备了资金。扶贫资金具体使用不够灵活，扶贫资金的分配往往体现了上级的意志， 与基层思路及脱贫实践有些许距离。

\section{4. 临沂农村精准脱贫的实现路径及对策}

\section{1 树立 “一切从贫困户需求出发” 的理念}

精准脱贫要从贫困农户的实际需求出发。所有精准扶贫政策和项目都应该满足贫困群体 合理需求, 提升其发展能力。对贫困农户要保持充分的尊重, 鼓励扶贫对象依靠自己的已有 
条件，优先进行自我发展。

\section{2 搭建各类扶贫主体协同参与的沟通平台}

临沂市范围内, 建议以地方乡镇政府为核心, 搭建各精准扶贫主体之间协调沟通的平台。 帮扶双方要以扶贫开发为重心, 以产业协作为关键, 以生态环境改造为基础, 从根本上激发 贫困户脱贫的内生动力，在巩固传统项目的基础上，拓展实施新的救助项目。

\section{3 调动农民主体的积极性}

首先, 以农民自愿参与作为原则, 开展精准扶贫工作, 发挥村民自身的主体、自治作用。 其次，彻底改变贫困农民原来等、靠、要的思想。

\section{4 保证政府的主导作用}

4. 4. 1. 采取信息公开的形式, 构建精准扶贫的信息平台, 将贫困区域的文化、习俗、气候、 地理、资源等各种相关信息, 详细地提供给扶贫企业, 通过相应的政策条件, 引导各扶贫企 业将自身优势与贫困地区的特色条件相结合，采取联合结对帮扶、村企共建、小企帮户、大 企包村等各种具体方式, 实施精准脱贫。

4. 4.2 通过各行业协会与商会的引导, 把企业的转型升级和农村精准脱贫有机结合, 鼓励企 业主动承担社会责任。对于返乡创业者，给予政策支持并积极鼓励。

4. 4. 3. 建立扶贫企业扶贫激励机制。采用适当的激励措施, 对在精准扶贫工作中, 作出显著 贡献的扶贫企业, 给予公开表彰, 并提供相应的优惠政策。根据扶贫企业精准扶贫的实际效 果，为其提供低息贷款，协助建立产业扶贫的相关风险保障体系等等。

\section{5 提升企业的主力地位}

4. 5.1 以农业产业项目为平台, 开展村企共建

首先，产业扶贫的开展，必须从扶贫实际出发，剖析导致贫困的根本原因。根据不同原 因, 因户施法、因村施策和因地制宜, 才能真正突出其 “造血” 功能。其次, 以农业产业项目 为平台, 发展村企共建模式。操作模式可为: 农民的土地经营权入股, 企业以市场化的方式 经营, 农民投入劳动力, 最终收益农民共享, 实现长效、持续的精准扶贫。再次, 与扶贫企 业建立项目、土地等合作关系。

4. 5.2. 根据地方需求, 建立特色农业基地

首先，扶贫企业要综合考虑各贫困区域的产业基础。因为各贫困地区的生态环境和资源 是千差万别的, 只有根据各区域的特色资源来选择和发展特色产业, 才能提高脱贫动力力和 生产力。其次, 扶贫企业要按照市场的需要来决定产业。只有弄清市场的需要, 按照消费结 构的升级, 才能推进农业供给侧结构性改革, 企业才能有更多的生存与发展空间。再次, 围 绕绿色选产业。要积极开发推进绿色相关产业, 同时考虑区域环境资源的生命周期和承载力, 统筹生产发展和生态保护, 确保当代农业产业的可持续发展。

\section{6 发挥学校的培养功能}

4. 6. 1. 根据贫困地区发展需求设置专业, 和企业共建产业化实训基地

首先, 学校要根据扶贫区域经济发展趋势和产业设置培养目标、办学形式和方向。其次, 与扶贫企业共同开办实训基地, 扶贫企业直接参与、支持贫困地区农民或学生的农业知识和 技能培训，采取多形式、多层次合作，促进她们熟练掌握农业技能。

\section{6. 2. 根据岗位和贫困户特点, 举办方向明确的技能精准培训}

首先，根据贫困区域农业产业的发展情况，结合未来岗位的需要，对青年农民进行农业 技术培训，以帮助贫困农民掌握各种实用技术，蜕变成技术型农村居民。再次，对愿回乡创 业的农民工, 根据其自身特点和实际产业需要, 进行经济作物种植、家庭养殖等生产操作的 技术培训。 


\section{6. 3. 加强师资队伍建设，聘请农业专家支持技术培训}

首先, 聘请农林高校和职业院校的优秀教师, 编写专业的培训教材、读本, 对贫困人群 进行科技推广和实训。其次, 根据不同村民的特点设计教学内容, 以实践为主, 把教学场地 安排在生产现场, 将学习与生产完美结合, 帮助贫困农民获取实用知识. 真正意义上掌握实际 操作的技巧。

\section{5. 结语及展望}

精准脱贫是一个繁杂的系统工程，政府、社会都有义务和责任来共同推进。扶贫不只是 各级政府的任务，应该动员全社会的力量协同实现；不要单纯依赖行政方法和能力，应该充 分采用市场配置，凭借社会资源、市场能量合力推进。

广泛动员社会力量, 充分发挥市场功能, 协调一致精准脱贫, 这只是一个开端。我们要 以此为开端，构造 “政府主导、社会参与、市场能动” 的精准扶贫模式，打造人人 “皆愿为、 皆可为、皆能为” 的扶贫格局，推进政府、社会和市场之间协调发展、各司其职、共同作用。

\section{致谢}

本文为临沂社科规划项目《政府、市场、社会三元驱动的临沂农村精准脱贫模式研究》 (2018LX215)的阶段性成果之一。

\section{References}

[1] Li Kun and Ye Xing-jian, Rural Precise Poverty Alleviation:Analysis on Theoretical Bases and Practical Situations, Journal of Fujian Administration Institute, vol., pp. 26-33+54, 2015.

[2] Zhang Zhixin and Yang Yuyu. The Exploration and Proposal of Aggie Butt Targeted Poverty Alleviation, Journal of Jiangsu University(Social Science Edition), vol.2(20), pp. 37-43, 2018.

[3] Wang wei and Li Ping, The Path Design of Targeted Poverty Alleviation in the Border Areas of Heilongjiang with the Goal of Prosperity, Journal of Harbin Institute of Technology(Social Sciences Edition), vol.2(20), pp. 38-44, 2018.

[4] Kong De-bin, Embedded Poverty Alleviation: a New Model of Poverty Alleviation, Theory and Reform, vol. 2, pp. 67-76, 2018.

[5] Zheng Yui-qiang and Cao Guo-qing, Major problems of poverty alleviation and relevant governance strategies in ethnic minority areas in the consolidation and improvement stage, Journal of Yunnan Minzu University(Social Sciences), vol. 2(35), pp. 98-104, 2018. 